\title{
High-mobility group A1 protein inhibits p53-mediated intrinsic apoptosis by interacting with $\mathrm{Bcl}-2$ at mitochondria
}

\author{
F Esposito ${ }^{1}$, M Tornincasa ${ }^{1}$, A Federico ${ }^{1}$, G Chiappetta ${ }^{2}$, GM Pierantoni ${ }^{1}$ and A Fusco ${ }^{*, 1,3,4}$
}

The high-mobility group A (HMGA) proteins are a family of non-histone chromatin factors, encoded by the HMGA1 and HMGA2 genes. Several studies demonstrate that HMGA proteins have a critical role in neoplastic transformation, and their overexpression is mainly associated with a highly malignant phenotype, also representing a poor prognostic index. Even though a cytoplasmic localization of these proteins has been previously reported in some highly malignant neoplasias, a clear role for this localization has not been defined. Here, we first confirm the localization of the HMGA1 proteins in the cytoplasm of cancer cells, and then we report a novel mechanism through which HMGA1 inhibits p53-mitochondrial apoptosis by counteracting the binding of p53 to the anti-apoptotic factor Bcl-2. Indeed, we demonstrate a physical and functional interaction between HMGA1 and Bcl-2 proteins. This interaction occurs at mitochondria interfering with the ability of p53 protein to bind Bcl-2, thus counteracting p53-mediated mitochondrial apoptosis. This effect is associated with the inhibition of cytochrome $c$ release and activation of caspases. Consistent with this mechanism, a strong correlation between HMGA1 cytoplasmic localization and a more aggressive histotype of thyroid, breast and colon carcinomas has been observed. Therefore, cytoplasmic localization of HMGA1 proteins in malignant tissues is a novel mechanism of inactivation of p53 apoptotic function.

Cell Death and Disease (2012) 3, e383; doi:10.1038/cddis.2012.126; published online 30 August 2012

Subject Category: Cancer

The mammalian high-mobility group A (HMGA) nuclear proteins are a family of non-histone chromatin-associated proteins. This family consists of four known members: HMGA1a, HMGA1b and HMGA1c, derived from an alternative splicing of the same gene, HMGA1, ${ }^{1,2}$ and HMGA2, encoded by the homonymous gene. ${ }^{3}$ HMGA proteins bind the minor groove of AT-rich DNA sequences through their DNAbinding domains, the so-called 'AT-hooks'. HMGA proteins do not have transcriptional activity per se, however, by interacting with the transcriptional machinery, they alter the chromatin structure and, thereby, regulate the transcriptional activity of several genes. ${ }^{4,5}$ The expression of HMGA proteins is high during embryogenesis and low or undetectable in normal adult tissues. ${ }^{6,7}$ Conversely, high HMGA expression has been observed in human malignant neoplasias, including thyroid, ${ }^{8}$ colon, ${ }^{9}$ prostate, ${ }^{10}$ pancreas, ${ }^{11}$ cervix, ${ }^{12}$ ovary,${ }^{13}$ and breast ${ }^{14}$ carcinomas. Moreover, their overexpression is mainly associated with a highly malignant phenotype, also representing a poor prognostic index, as HMGA overexpression often correlates with the presence of metastases, and with a reduced survival. ${ }^{15} \mathrm{~A}$ functional role of this aberrant HMGA overexpression in cancer has been previously demonstrated by in vitro and in vivo studies. Indeed, we have previously demonstrated that overexpression of HMGA proteins is required for cell transformation, as the blockage of their synthesis prevents tumorigenic transformation of rat thyroid cells by murine-transforming retroviruses, ${ }^{16}$ and infection with a recombinant adenovirus carrying the $H M G A 1 b$ complementary DNA in antisense orientation led several carcinoma cell lines to death. ${ }^{17}$ Moreover, transgenic mice overexpressing either the Hmga1 or Hmga2 gene develop benign and malignant neoplasias. ${ }^{15}$

Recently, we have identified a novel mechanism, based on HMGA1-p53 interaction, by which HMGA1 proteins have a role in the process of carcinogenesis. HMGA1 binds p53, and interferes with the p53-mediated transcription of $B a x, p 21^{\text {waf1 }}$, $\mathrm{Mdm} 2$ and $\mathrm{BCl}-2$ leading to a reduction of p53-dependent apoptosis. ${ }^{18,19}$ Indeed, HMGA1 counteracts the p53 transcriptional activity also through the relocalization of the p53 proapoptotic activator homeodomain-interacting protein kinase 2 from nucleus to the cytoplasm, thus inhibiting p53 apoptotic function. ${ }^{20}$

Even though the HMGA1 proteins have been frequently detected in the cytoplasm of cancer cells, ${ }^{14}$ these data have

\footnotetext{
${ }^{1}$ Istituto di Endocrinologia ed Oncologia Sperimentale del CNR c/o Dipartimento di Biologia e Patologia Cellulare e Molecolare, Facoltà di Medicina e Chirurgia di Napoli, Università degli Studi di Napoli 'Federico Il', Naples, Italy; ${ }^{2}$ Istituto Nazionale dei Tumori, Fondazione Pascale, via Mariano Semmola, Naples, Italy; ${ }^{3}$ NOGEC (Naples Oncogenomic Center)-CEINGE-Biotecnologie Avanzate, Naples, Italy and ${ }^{4}$ SEMM - European School of Molecular Medicine - Naples Site, Naples, Italy

${ }^{*}$ Corresponding author: A Fusco, Istituto di Endocrinologia ed Oncologia Sperimentale del CNR c/o Dipartimento di Biologia e Patologia Cellulare e Molecolare, Facoltà di Medicina e Chirurgia di Napoli, Università degli Studi di Napoli 'Federico Il', via Sergio Pansini 5, 80131 Napoli, Italy. Tel: + 390817463602 ; Fax: + 39081 2296674; E-mail: alfusco@unina.it

Keywords: HMGA proteins; p53; Bcl-2; apoptosis; mitochondria

Abbreviations: HMGA, high mobility group A; Bcl-2, B-cell lymphoma gene-2; UV, ultra violet; HA, haemagglutinin; MEFs, mouse embryonic fibroblasts; EGFP, enhanced green fluorescent protein; TCE, total cell extract; CCE, cytoplsmic cell extract; MOMP, mitochondrial outer membrane permeabilization; WGA, wheat germ agglutinin

Received 22.2.12; revised 17.7.12; accepted 24.7.12; Edited by RA Knight
} 
been often considered as an artefact likely due to a very abundant HMGA1 expression. Therefore, the aim of our studies was to clearly demonstrate the presence of these proteins in the cytoplasm and unveil the functional role of this localization.

Here, we report that the HMGA1 proteins are present at cytoplasmic level, other than in the nucleus, in several tumorderived cell lines and tumor tissues overexpressing these proteins. Moreover, we demonstrate that the HMGA1 proteins stably localize at the mitochondria, in which it binds Bcl-2, displacing it from the binding to p53, thus counteracting the release of cytochrome $c$ from mitochondria. Consistently, the cells overexpressing HMGA1 at cytoplasmic level show a significant reduction of cytochrome $c$ release and apoptotic rate after lethal dose of ultraviolet (UV) light.

Therefore, these data demonstrate the localization of HMGA1 at the mitochondria where it inhibits p53 intrinsicapoptotic pathway through a transcription-independent mechanism.

\section{Results}

HMGA1 is present at cytoplasmic level other than in the nucleus. To determine whether HMGA1 proteins localize also at cytoplasmic level, we analyzed differential cell fractions from human embryonic kidney 293 cells (HEK293) transiently transfected with vectors encoding the full-length haemagglutinin $(\mathrm{HA})$-tagged HMGA1b protein and a series of $\mathrm{NH} 2$ - and $\mathrm{COOH}$-terminal deletion mutants (Figure 1a). Western blot analysis showed that the proteins coded for by the full-length HA-HMGA1b and almost all the HA-HMGA1b deletion mutant constructs were present in both the nuclear and cytoplasmic extracts (Figure 1b). One exception was represented by the HA-HMGA1b (1-43) construct that showed only a cytoplasmic localization (Figure 1b). Sp1 and $\gamma$-tubulin were used as markers of nuclear/cytoplasmic separation as well as loading controls (Figure $1 \mathrm{~b}$ ).

To confirm these data, immunofluorescence studies, using $\mathrm{HA}$ antibodies and a marker that selectively stains nucleus (Hoechst), were performed analyzing HMGA1 localization in HEK293 cells transiently transfected as described above. The results shown in Figure 1c confirm that the HMGA1 full-length protein was detected in both the nuclear and cytoplasmic compartments after transfection with almost all the constructs, whereas the protein coded for by the HA-HMGA1b (1-43) construct was located only in the cytoplasm.

To confirm the cellular localization of endogenous HMGA1 proteins, we analyzed total, nuclear, and cytoplasmic cell lysates from several tumor- and non-tumor-derived cell lines. Western Blotting analyses demonstrated that HMGA1 was present at cytoplasmic level, other than in the nucleus, in several breast (BT549, MDA-MB-231, MDA-MB-468), lung (H1299), cervical (HeLa) cancer cell lines (Figure 2a), whereas it was detected only at nuclear level in noncancerous cell lines, such as HEK293, neuronal cell line (ND7), spermatogonia cell line (GC1) (Figure 2b) and in three breast carcinoma cell lines (T47D and MCF7) (Figure 2a). Only in the HBL100, a noncancerous breast cell line, HMGA1 was present at cytoplasmic level, other than in the nucleus. Interestingly, mouse embryonic fibroblasts (MEFs) behaved as most of the cancer cell lines showing HMGA1 expression in both the compartments (Figure 2a). Furthermore, HMGA1 was present at nuclear and cytoplasmic level also in human seminomas, whereas it was only nuclear in the normal testis (Figure 2a).

It is noteworthy that when the same experiments were performed to analyze the cellular localization of the other member of the HMGA protein family, HMGA2, this protein was not detected at cytoplasmic level, but only in the nucleus (Figures $1 b$ and $c$ ). This result suggests that the cytoplasmic localization is restricted to the HMGA1 member of the HMGA protein family.

HMGA1 localizes in the internal compartments and on the outer membrane of mitochondria. As, we identified, by an Antibody Array, the Bcl-2 protein, known to be located at mitochondria, as a new possible interacting partner of HMGA1 (Pierantoni and Esposito, unpublished data), we decided to further characterize the sublocalization of HMGA1 into the cytoplasm and its association with mitochondria.

To further characterize the role of HMGA1 into the cytoplasm and its association with mitochondria, we performed an immunofluorescence assay in HEK293 cells transfected with a vector encoding EGFP-HMGA1b protein and incubated with a marker that selectively stains mitochondria (MitoTracker Red dye). Merging of the signals by microscopy supported the partial localization of the cytoplasmic EGFP-HMGA1b protein fraction at the mitochondria (Supplementary Figure S1). Therefore, to determine the mitochondrial compartment in which HMGA1 is located, we performed an enzymatic digestion of mitochondrial fractions from HMGA1b- and empty vector-transfected HEK293 (Figure 2c) and MDA-MB-231 cells, that show the presence of HMGA1 at cytoplasmic level (Figure 2d). After digestion with proteinase $\mathrm{K}$, a non-specific protease unable to cross the outer mitochondrial membrane, ${ }^{21}$ HMGA1 was partially recoverable in the pellet, whereas $\mathrm{Bcl}-2$, a tail-anchored protein to the mitochondrial membrane, was degraded. HMGA1 disappeared, as it occurs also for p53, only after solubilization of inner mitochondrial membranes by Triton $\mathrm{X}$, indicating that it is located in the internal compartments and on the outer membrane of mitochondria (Figures $2 c$ and $d$ ).

HMGA1 binds to Bcl-2 in vitro and in vivo. To characterize the role of HMGA1 proteins into the cytoplasm, we looked for new molecular partners. Because Bcl-2 localizes to mitochondrial outer and, to a lesser degree, inner membrane, ${ }^{22}$ and $\mathrm{Bcl}-2$ has been recently identified as a possible HMGA1-interacting partner by an Antibody Array (Pierantoni and Esposito, unpublished data), we asked whether HMGA1 is able to bind $\mathrm{Bcl}-2$. To this aim, we first evaluated the ability of HMGA1 and Bcl-2-purified proteins to interact in vitro. Indeed, $\mathrm{Bcl}-2$ recombinant protein was incubated with the HisHMGA1b protein and the complexes were immunoprecipitated with anti-HMGA1 or anti-Bcl-2 antibodies and analyzed by western blotting with the reciprocal antibodies. As shown in the Figure 3a, HMGA1 and Bcl-2 proteins can directly interact. To verify this interaction in vivo, total cell extracts from HEK293 cells transiently transfected with pCEFL-HA and pCEFL-HA/HMGA1b constructs were immunoprecipitated with anti-HA monoclonal antibodies and analyzed by western 
a

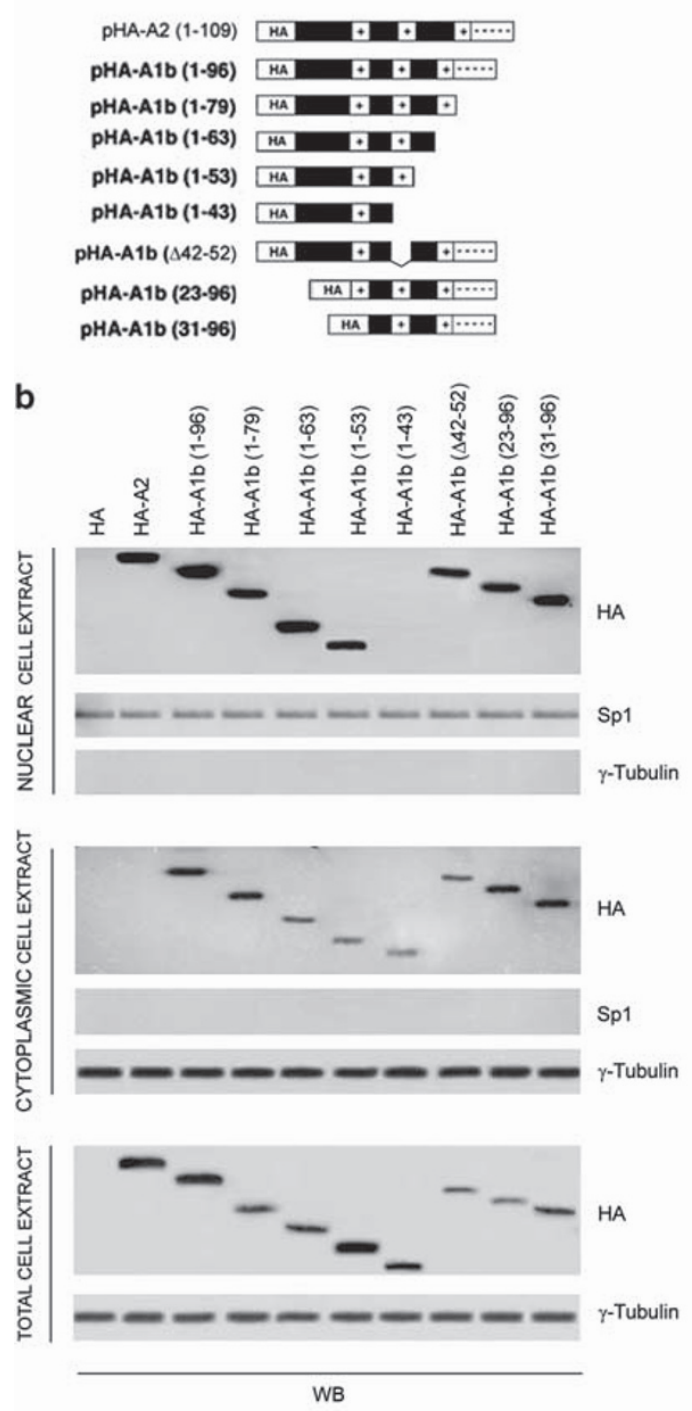

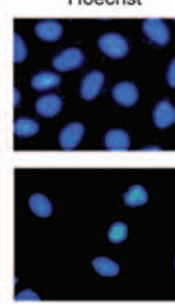
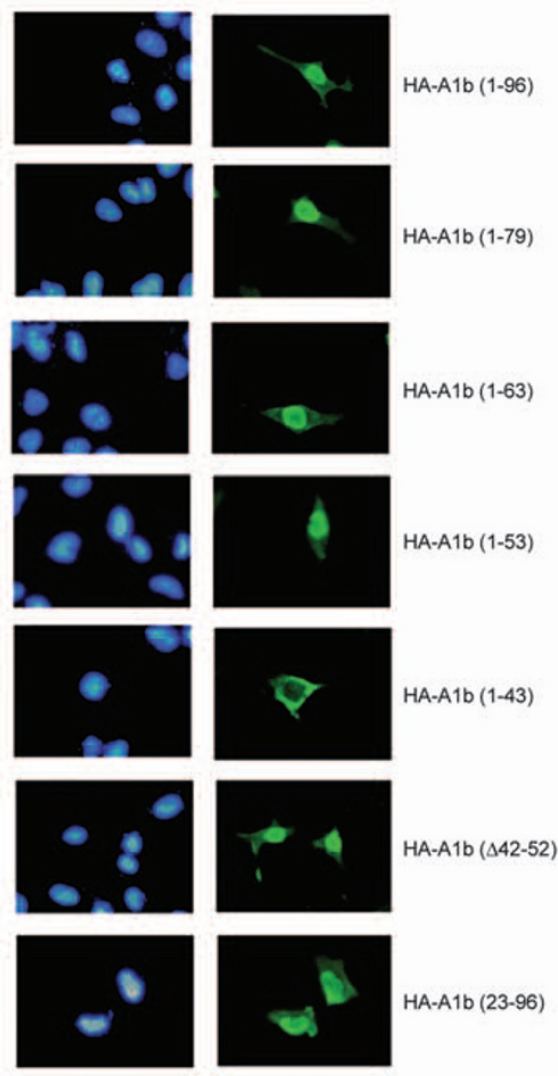

HA-A1b (23-96)
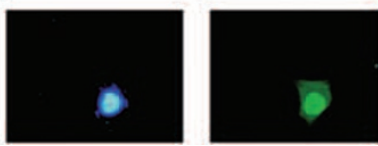

HA-A1b (31-96)

Figure 1 HMGA1 is stably present at cytoplasmic level. (a) Diagram of the HA-tagged Hmga2 and wild-type and Hmga1 deletion mutants used in western blotting and immunofluorescence analysis. The AT-hook domains $(+)$ and the acidic tail (- - - - ) are indicated. (b) Nuclear, cytoplasmic and total cell extracts from HEK293 cells were analyzed by western blotting for the expression of the constructs. Sp1 and $\gamma$-tubulin were used as markers of nuclear/cytoplasmic separation as well as loading controls. (c) Subcellular localization of HA-HMGA2 and HA-HMGA1 mutant proteins in HEK293 cells transfected with the indicated vectors. Nuclei were stained with Hoechst

blotting with anti-Bcl-2 polyclonal antibodies. Bcl-2 protein was present in the immunocomplexes from HA-HMGA1b-transfected cells (Figure $3 b$, upper panel). The reciprocal experiment performed immunoprecipitating with anti-Bcl-2 antibodies and revealing with anti-HMGA1 antibodies confirmed this interaction (Figure 3b, lower panel). Moreover, we have detected this association also between the endogenous proteins in the cytoplasmic cell extract (CCE) from MDA-MB231 cells (Figure $3 c$ ).

HMGA1 displaces Bcl-2 from the binding to p53. We have previously demonstrated a physical and functional interaction between HMGA1 and p53. ${ }^{18}$ This interaction modulates the transcription of p53 target genes, such as
Mdm2, p21 $1^{\text {waf1 }}, \mathrm{Bax}, \mathrm{Bcl}-2$, inhibiting p53-mediated apoptosis. ${ }^{18-20}$ As suggested by the data shown above, we asked whether HMGA1 counteracts p53-mediated apoptosis acting also through the p53 interactors in the cytoplasm, in particular at mitochondria.

It is known that the cytochrome $c$ release mediated by p53 depends on its ability to bind members of the anti-apoptotic $\mathrm{Bcl}-2$ family (i.e. Bcl-2 and $\mathrm{Bcl}-\mathrm{xL}$ ) and to inactivate their inhibitory effect exerted on the proapoptotic proteins Bax and Bak. ${ }^{23,24}$ Therefore, we investigated whether HMGA1 affects p53 binding to $\mathrm{Bcl}-2$ by performing a co-immunoprecipitation assay in the HEK293 cells incubated with doxorubicin, that is able to activate the endogenous p53, in the presence or absence of HMGA1b protein overexpression. As expected, 
a

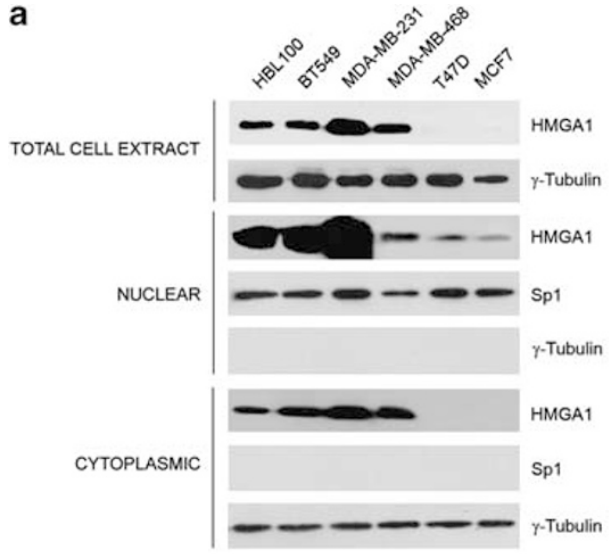

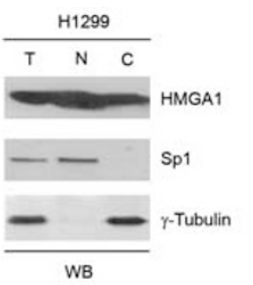

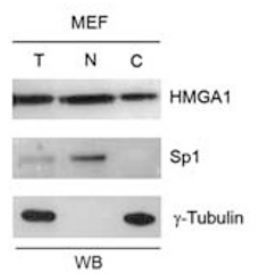

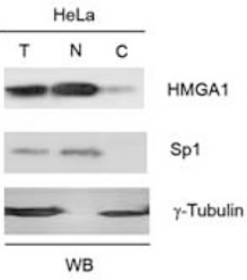

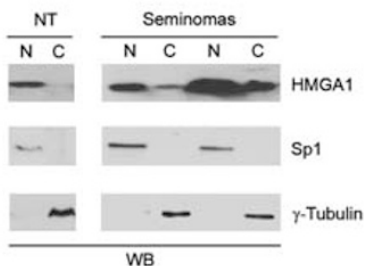

b
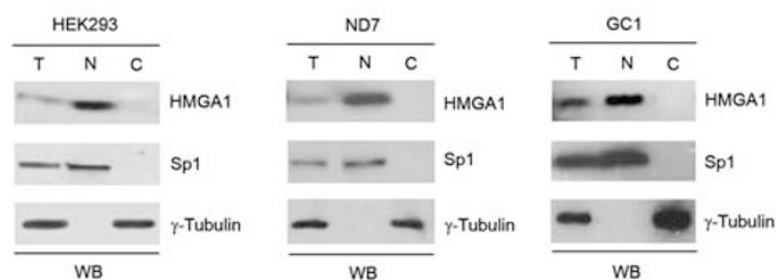

C

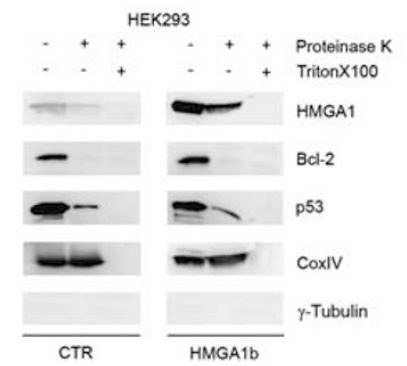

d

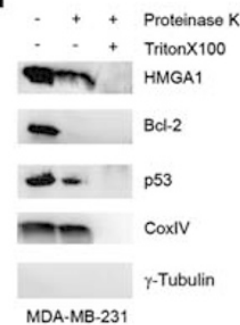

Figure 2 HMGA1 is located into the cytoplasm of cancer-derived cell lines and in MEFs. (a) Immunoblot analysis of HMGA1 expression in total (T), nuclear (N) and cytoplasmic (C) cell extracts from several breast tumor cell lines (BT549, MDA-MB-231, MDA-MB-468, T47D, MCF7), breast cell line (HBL100) (left), lung cancer cell line (H1299), cervical cancer cell line (HeLa), mouse embryonic fibroblasts (MEFs), human normal testis and seminomas (right). (b) Total (T), nuclear (N) and cytoplasmic (C) cell extracts from HEK293, ND7 and GC1 cells were analyzed by western blotting for the HMGA1 protein. Sp1 and $\gamma$-tubulin were used as markers of nuclear/cytoplasmic separation as well as loading controls. HMGA1 localizes at the mitochondria in the internal compartments and on the outer membrane. (c) Mitochondrial fractions from control and HMGA1b-transfected HEK293 cells were enzymatically digested by Proteinase K in the presence or absence of Triton X-100 (1\%) and subsequently analyzed by western blotting for the indicated proteins. (d) Mitochondrial fractions from MDA-MB-231 cells were treated as in $\mathbf{c}$ and analyzed by western blotting for the indicated proteins. Cyclooxygenase IV (CoxIV), located to the inner mitochondrial membrane, was used as loading control. Cytosolic contamination was verified by western blotting using anti- $\gamma$-Tubulin antibodies

doxorubicin increases the formation of the Bcl-2/p53 complex leading to cell death, whereas HMGA1b overexpression significantly reduces the Bcl-2/p53 binding (Figure 3d). The same results were obtained in MCF7 cells (data not shown).

To confirm this result, we used a cell-free system in which p53 and Bcl-2 recombinant proteins were incubated in presence or absence of the recombinant wild-type HMGA1b protein. As shown in Figure 3e, HMGA1b recombinant protein displaced $\mathrm{Bcl}-2$ from the binding to $\mathrm{p} 53$.

These findings demonstrate that HMGA1b directly interferes with the $\mathrm{p} 53 / \mathrm{Bcl}-2$ binding.

HMGA1 counteracts p53-intrinsic apoptosis. p53 activates the apoptosis through two distinct pathways: transcriptional activation of proapoptotic genes and facilitation of mitochondrial outer membrane permeabilization with release of cytochrome $c^{25,26}$ The data shown above strongly suggest that the presence of HMGA1 at mitochondria affects p53-mediated mitochondrial apoptosis (also called p53intrinsic apoptosis) through the reduction of p53/Bcl-2 binding.

Earlier studies have demonstrated that p53-intrinsic apoptosis is due to the ability of p53 to permeabilize membranes of isolated mitochondria and permit cytochrome $c$ release ${ }^{23-25}$ Therefore, we investigated whether HMGA1 counteracts p53mediated mitochondrial outer membrane permeabilization in a cell-free system by testing the ability of recombinant p53 to permeabilize mitochondria isolated from HEK293 or MCF7 cells in presence or absence of HMGA1b recombinant protein. As expected, p53 caused release of cytochrome $c$ from HEK293 and MCF7 mitochondria (Figure 4a), whereas the presence of HMGA1 greatly reduced such release resulting in the depletion of cytochrome $c$ from the 
a

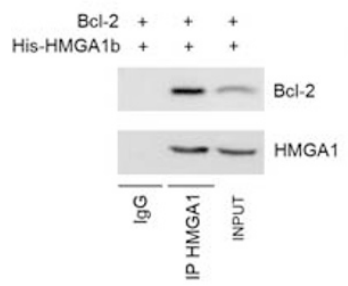

b

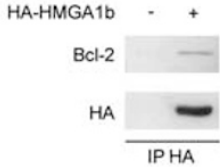

HA-HMGA1b - +

HMGA1

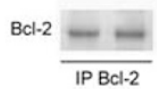

C
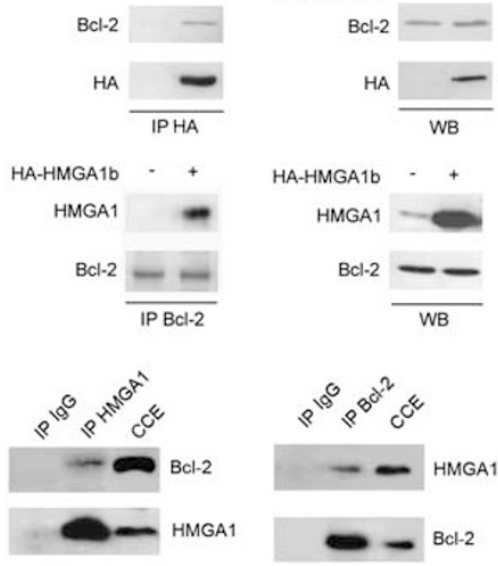

d Doxorubicin - * + +

HMGA1b - - - +

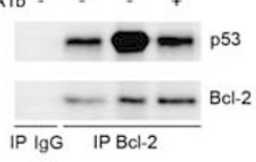

Doxorubicin - ++

HMGA1b
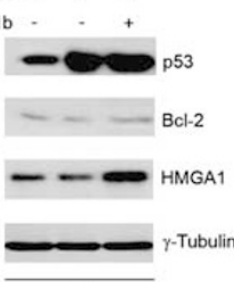

WB
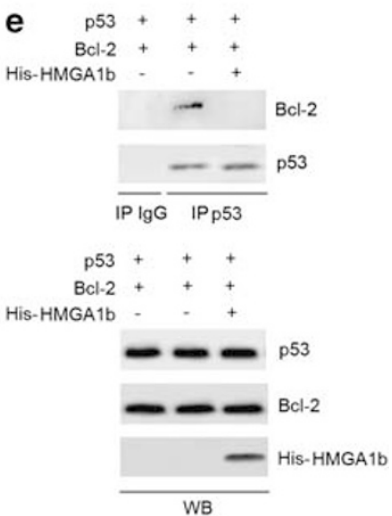

Figure 3 In vitro and in vivo characterization of the HMGA1/Bcl-2 interaction. (a) The in vitro interaction between HMGA1b and Bcl-2 was assessed by immunoprecipitation assay with anti-HMGA1 (left panel) or anti-Bcl-2 (right panel) antibodies and blotting with the reciprocal antibodies after preincubation of the two proteins. The relative inputs are the His-HMGA1b and Bcl-2 recombinant proteins (loaded as controls). (b) HEK293 cells were transfected with pCEFL-HA and pCEFL-HA/Hmga1b vectors. After $48 \mathrm{~h}$, total cell extracts were prepared and equal amounts of proteins were immunoprecipitated with anti-HA (upper panel) or anti-Bcl-2 (lower panel) antibodies, and the immunocomplexes were analyzed by western blotting using the reciprocal antibodies. Cellular extracts used for immunoprecipitation experiments were analyzed by western blotting (right panels). (c) Co-immunoprecipitation with the anti-HMGA1 or anti-Bcl-2 antibodies on the cytoplasmic endogenous HMGA1 and Bcl-2 proteins (CCE from parental MDA-MB-231 cells). IgG indicates the negative control of immunoprecipitation using unrelated antibodies. HMGA1 displaces Bcl-2 from the binding to p53. (d) Lysates from HEK293 cells transfected with control or HMGA1b-expressing vectors and treated or not with doxorubicin were subjected to immunoprecipitation with anti-Bcl2 antibodies, and then immunocomplexes were analyzed by western blotting using p53 antibodies. Western blot with Bcl-2 antibodies was used as a control of the equal loading of the immunoprecipitated Bcl-2 protein (upper panel). Cellular extracts used for immunoprecipitation experiments were analyzed by western blot with specific antibodies to verify protein expression levels (lower panel). $\gamma$-Tubulin expression was used as a control for equal protein loading. (e) p53 and Bcl-2 recombinant proteins were co-immunoprecipitated in the presence or absence of His-HMGA1b recombinant protein. The samples were separated by SDS-PAGE and transferred onto Immobilon-P membranes. The filters were probed with either p53 or Bcl-2 antibodies (upper panel). Western blotting analysis shows the amount of recombinant proteins used (lower panel)

supernatant fraction. These data strongly support the existence of a negative role of mitochondrial-localized HMGA1 on the p53 permeabilization function.

To verify whether the mitochondrial localization of HMGA1 has functional effects, HEK293 and MCF7 cells were transfected with $H M G A 1 b$-expressing vector and treated with a lethal dose of UV $\left(40 \mathrm{~J} / \mathrm{m}^{2}\right)$ to induce cytochrome $c$ release mediated by $\mathrm{p} 53$ activity.

After UV treatment, no induction of cytochrome $c$ release into the cytosolic fraction could be observed in HEK293 and MCF7 cells transfected with HMGA1b expression vector in comparison with the backbone-vector-transfected cells at the indicated times (Figures $4 \mathrm{~b}$ and $\mathrm{c}$ ). A similar kinetics of mitochondrial cytochrome $c$ release was observed in $\mathrm{H} 1299$ cells, where co-overexpression of $\mathrm{p} 53$ and $\mathrm{HMGA} 1$ resulted in a significant reduction of p53 activity on cytochrome $c$ release (data not shown).
The inhibitory effect of HMGA1 on p53-induced cytochrome $c$ release was further confirmed by analyzing mitochondrial and cytosolic fractions isolated from wild-type and MEFs null for the hmga1 gene after UV irradiation. Figure 4d shows that UV light was less efficient in triggering the release of cytochrome $c$ from the mitochondria of wild-type MEFs compared with those from hmga1 - / - MEFs. Consistently, we found an increased percentage of apoptotic cells in hmga1 - I - MEFs after UV irradiation in comparison with the control cells (Figure 4e). Moreover, HEK293 cells overexpressing HMGA1b protein showed a reduction of Caspase 9 cleavage and a decreased number of apoptotic cells after UV irradiation in comparison with the control cells (Figure 4f, left panel and middle panel, respectively). In particular, the analysis of mitochondrial potential showed an increased resistance of HMGA1-overexpressing cells to the collapse of the electrochemical gradient across the mitochondrial membrane 
a

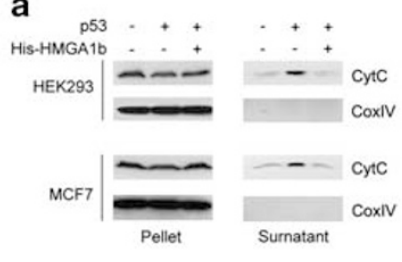

C

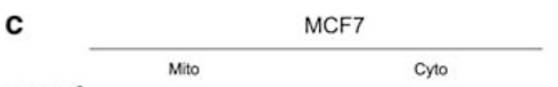

UV $40 \mathrm{~J} / \mathrm{m}^{2}$ on $2 \mathrm{~h} 4 \mathrm{~h}$ on $2 \mathrm{~h} 4 \mathrm{~h} \quad$ Oh $2 \mathrm{~h} 4 \mathrm{~h}$ on $2 \mathrm{~h} 4 \mathrm{~h}$

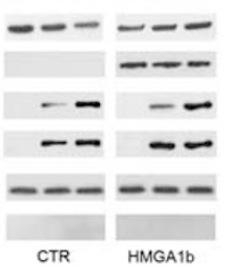

e
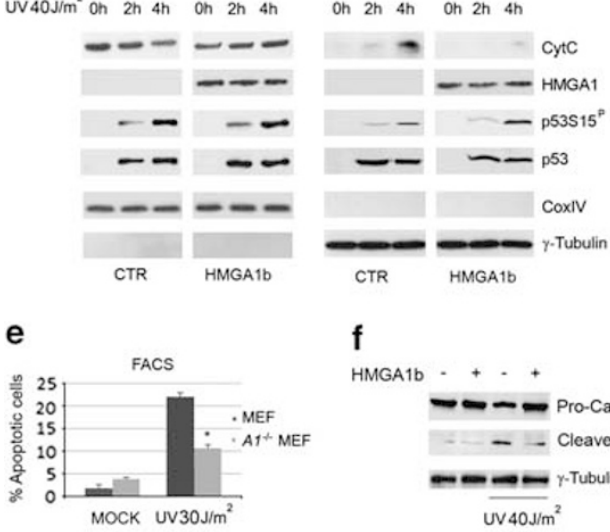

f

HMGA1b - + . +

b UV $40 . \mathrm{J}^{2}$ on $2 \mathrm{~h} \quad 4 \mathrm{~h}$ Cyto

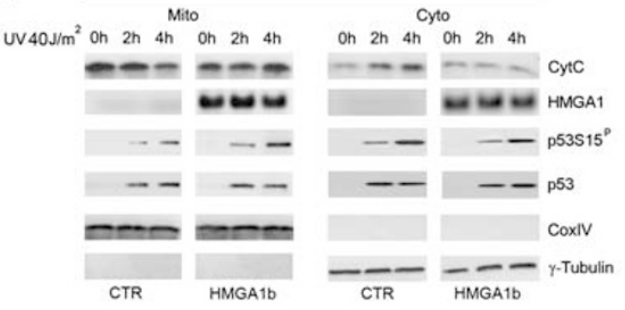

d
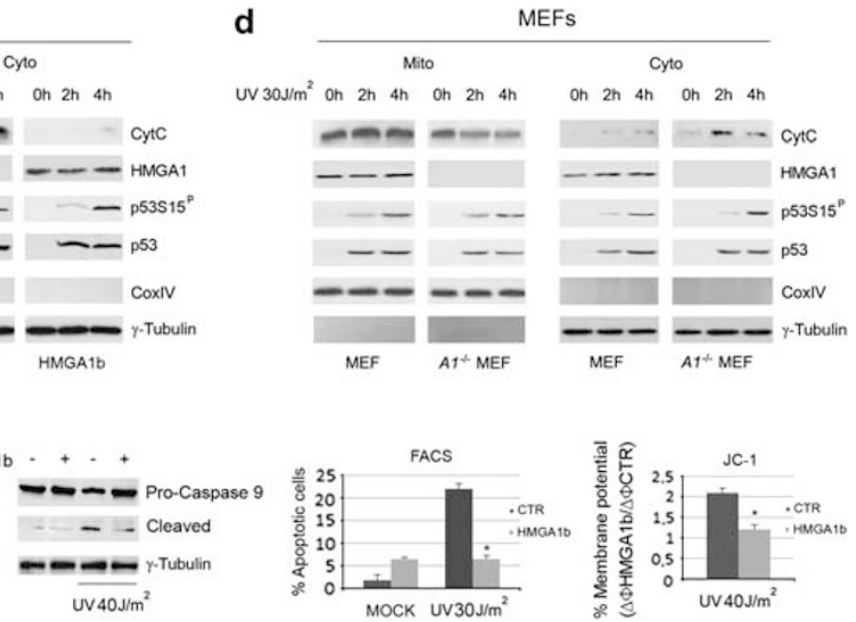

Figure 4 HMGA1 counteracts p53-mediated release of cytochrome $c$. (a) Mitochondria isolated from HEK293 and MCF7 cells transfected with HMGA1 or the backbone vectors were incubated with p53 recombinant protein. After 60 min incubation at $37^{\circ} \mathrm{C}$, reactions were centrifuged, and pellet and supernatant fractions analyzed by western blot. (b and c) HEK293 and MCF7 cells were transfected with HMGA1-expressing vector and, after $24 \mathrm{~h}$, cells were treated or not with $40 \mathrm{~J} / \mathrm{m}^{2}$ of UV irradiation. At the indicated time points, mitochondrial and cytosolic fractions were collected and analyzed by western blotting with the indicated antibodies. (d) Wild-type and $h m g a 1$ null MEFs were either untreated or treated with $30 \mathrm{~J} / \mathrm{m}^{2}$ of UV irradiation. At the indicated time points, mitochondrial and cytosolic fractions were collected and analyzed by western blotting. Cytosolic and mitochondrial contamination was verified by CoxIV and $\gamma$-Tubulin used also as loading control. (e) Wild-type and $h m g a 1$ null MEFs were treated as in $\mathbf{d}$, and apoptosis was assessed counting the number of apoptotic cells by FACS. (f) HEK293 cells were treated as in $\mathbf{b}$, and apoptosis was assessed by western blotting analysis of Caspase-9 cleavage (left panel), counting the number of apoptotic cells by FACS (middle panel) or analyzing mitochondrial membrane potential by JC-1 staining (right panel). Data are shown as percentage of increase of membrane potential of HMGA1-overexpressing cells with respect to the control cells at the indicated time points. The ratio (D $\Phi H M G A 1 b /$ $D \Phi C T L)$ was calculated after normalization of each $D \Phi$ to that of the corresponding untreated cells. The results are reported as the mean of three independent experiments with error bars indicating S.D. (mean \pm S.D.) $\left(t\right.$-test, $\left.{ }^{*} P<0.05\right)$

supporting a negative role for HMGA1 in mitochondrialintrinsic apoptosis (Figure 4f, right panel). Conversely, nuclear and/or cytoplasmic HMGA1 was not able to inhibit apoptosis after UV treatment in p53-null H1299 cells sustaining that the anti-apoptotic function of HMGA1 is necessarily dependent on p53 (data not shown).

HMGA1 inhibits p53-mediated apoptosis by a transcriptional-independent mechanism. It has been already demonstrated that HMGA1 binds to p53 and inhibits its transcriptional activity. Therefore, to exclude that HMGA1 might regulate mitochondrial function and inhibit apoptosis through mechanisms independent from its mitochondrial localization altering p53 transcriptional activity, HEK293 cells were treated with $\alpha$-amanitin, a specific inhibitor of polymerase II-dependent transcription and an activator of p53mitochondrial apoptosis. ${ }^{27}$ In the presence of $\alpha$-amanitin, overexpression of HMGA1 was still able to reduce the number of HEK293 cells with depolarized mitochondria (Figure 5a). As expected, HMGA1 was also able to reduce the percentage of apoptotic cells (Figure $5 b$ ) and Caspase 9 activation (Figure 5c) following treatment with $\alpha$-amanitin in comparison with the control cells. The same results were obtained in MCF7 cells, where HMGA1 overexpression counteracts Caspase 7 and Caspase 9 cleavages after $\alpha$-amanitin treatment (Figure $5 \mathrm{~d}$ ). Furthermore, the HAHMGA1b (1-43) deletion mutant protein, which localizes only into the cytoplasm and binds to Bcl-2 (Figure 5e), was still able to inhibit Caspase 9 activation following UV exposure, likely sustaining $\mathrm{Bcl}-2$ activity. Indeed, the HAHMGA1b (1-43) deletion mutant protein only partially counteracts apoptosis in comparison with the HA-HMGA1b full-length protein (Figure 5f). Consistently, the HA-HMGA1b (1-43) deletion mutant protein shows no transcriptional activity on p53 target genes, such as PUMA and NOXA (Figure 5g). Finally, we confined HMGA1 into cytoplasm, blocking its transcriptional activity, by using an inhibitor of nuclear import, wheat germ agglutinin (WGA). As expected, after UV exposure, we found a reduced percentage of apoptotic cells (Figure $5 \mathrm{~h}$ ).

Therefore, these results confirm the transcription-independent anti-apoptotic activity of HMGA1. 


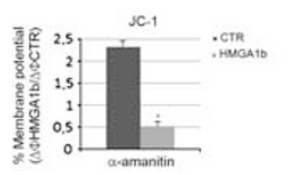

b

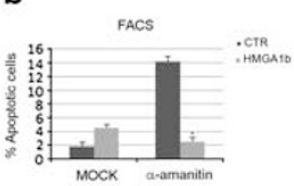

C

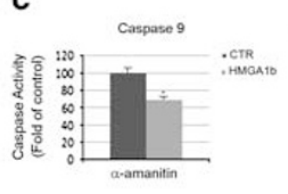

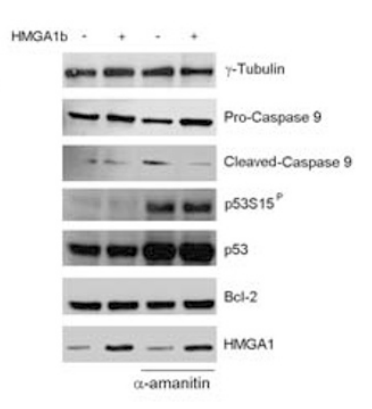

d

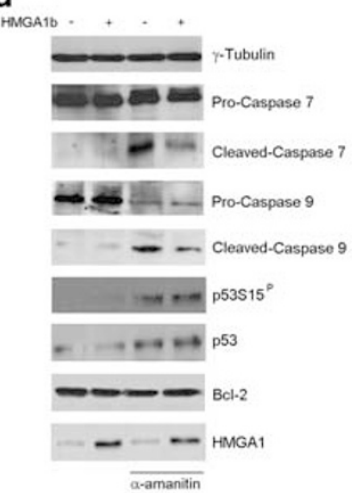

e

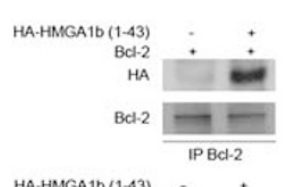

HA.HMGA1D (1-43) - .

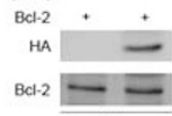

WB f

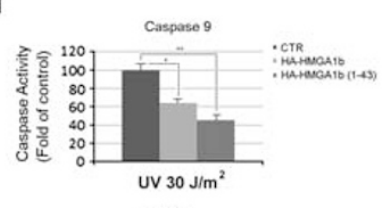

TUNEL.

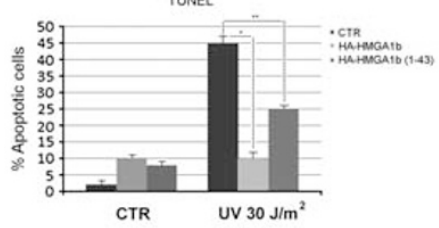

g

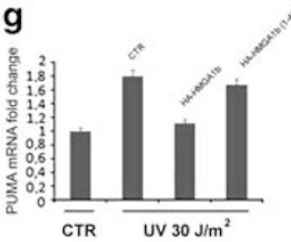

h
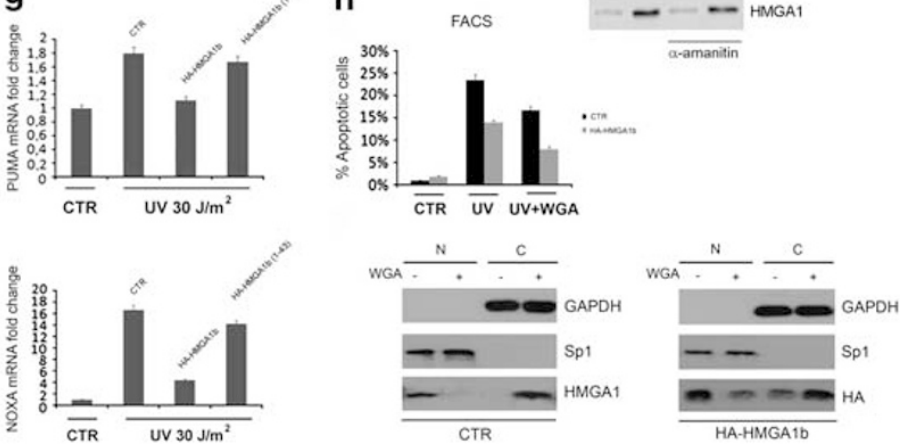

Figure 5 Transcription-independent activity of HMGA1 on apoptosis inhibition. (a-c) HEK293 cells were transfected with HMGA1 or the backbone vectors and after $24 \mathrm{~h}$ either untreated or treated with $10 \mu \mathrm{g} / \mathrm{ml} \alpha$-amanitin. After $16 \mathrm{~h}$, cell death was assessed by JC-1 assay (a), by counting the number of apoptotic cells by FACS (b), by Caspase- 9 colorimetric assay and western blotting analysis of Caspase- 9 cleavage (c). The results are reported as the mean of three independent experiments with error bars indicating S.D. (mean \pm S.D.) (t-test, ${ }^{*} P<0.05$ ). (d) MCF7 cells were treated as in a and apoptosis was assessed by western blotting analysis of Caspase-7 and Caspase-9 cleavage. (e) The interaction between HMGA1b (1-43) and Bcl-2 was assessed by immunoprecipitation assay with anti-Bcl-2 antibodies and blotting with anti-HA (upper panel). Cellular extracts used for immunoprecipitation experiments were analyzed by western blotting (lower panel). (f) HEK293 cells were transfected with control, HA-HMGA1b or HA-HMGA1b (1-43) expressing vectors and after $24 \mathrm{~h}$ either untreated or treated with $30 \mathrm{~J} / \mathrm{m}^{2}$ of UV irradiation. After $16 \mathrm{~h}$, cell death was assessed by Caspase-9 colorimetric assay (upper panel) and Tunel assay (lower panel). The results are reported as the mean of three independent experiments with error bars indicating S.D. (mean \pm S.D.) (t-test, ${ }^{*} P<0.05$, $\left.{ }^{*} P<0.05\right)$. (g) qRT-PCR analysis of PUMA and NOXA mRNA in the same samples shown in $f$. The fold-change values indicate the relative change in PUMA and NOXA expression levels normalized with G6PD. (h) Both control and HA-HMGA1b-overexpressing MCF7 cells were treated with WGA, confining HMGA1b into cytoplasm. After UV exposure $\left(50 \mathrm{~J} / \mathrm{m}^{2}\right)$, cell death was assessed by counting the apoptotic cells by FACS (upper panel). HMGA1 subcellular localization was analyzed by western blotting in nuclear (N) and cytoplasmic (C) cell extracts from MCF7 cells. Sp1 and GAPDH were used as markers of nuclear/cytoplasmic separation as well as loading controls (lower panel). The results are reported as the mean of three independent experiments with error bars indicating S.D. (mean \pm S.D.)

Cytoplasmatic localization of HMGA1 correlates with higher aggressive tumor histotype. The interaction of HMGA1 protein with $\mathrm{Bcl}-2$ and the consequent possible impairment of the p53 apoptotic activity would suggest another oncogenic effect of HMGA1, other than due to its regulation of the cell transcriptional activity, and thereby a higher aggressiveness of the cells where HMGA1 is located at the cytoplasmic level. Therefore, we analyzed the expression and localization of the HMGA1 protein in differentiated and undifferentiated thyroid carcinomas by immunohistochemistry. As shown in Figure 6, representative papillary and follicular thyroid carcinomas, that are welldifferentiated and poorly aggressive carcinomas, showed a specific nuclear staining for HMGA1 (Figures $6 a$ and b, respectively). Conversely, anaplastic thyroid carcinomas, that represent one of the most aggressive tumor in the mankind, evidenced a strong cytoplasmic staining (a representative case is shown in Figure 6c). Equally, a strong HMGA1 cytoplasmic staining was also found in aggressive breast and colon carcinomas (representative cases are shown in Figures $6 e$ and $g$, respectively), whereas in situ breast ductal carcinomas and colon adenomas showed nuclear-specific staining for HMGA1 (representative cases are shown in Figures $6 d$ and $f$, respectively). A summary of these immunohistochemical analyses is shown in Figure 6h and Table 1.

Taken together, these data indicate a correlation between HMGA1 positivity at cytoplasmic level and a higher aggressive tumor histotype.

\section{Discussion}

The overexpression of the HMGA proteins is a feature of several human malignancies, and it is clearly demonstrated that it has a critical role in the process of carcinogenesis, as the block of their expression inhibits cell transformation. It is accepted by the scientific community that HMGA localization is almost exclusively nuclear, and that HMGA proteins exert their oncogenic activity acting at transcriptional level. Indeed, it has been reported that they are able to:

(a) induce the activity of the transcription factor $\mathrm{E} 2 \mathrm{~F} 1^{28}$ and transcriptional AP-1 complex; ${ }^{29}$ (b) induce Cyclin A expression; ${ }^{30}$ (c) inactivate p53-induced apoptosis; ${ }^{18-20}$ (d) impair DNA repair; ${ }^{31}$ (e) enhance the expression of proteins involved in inflammation; ${ }^{32}$ (f) modulate the expression of 

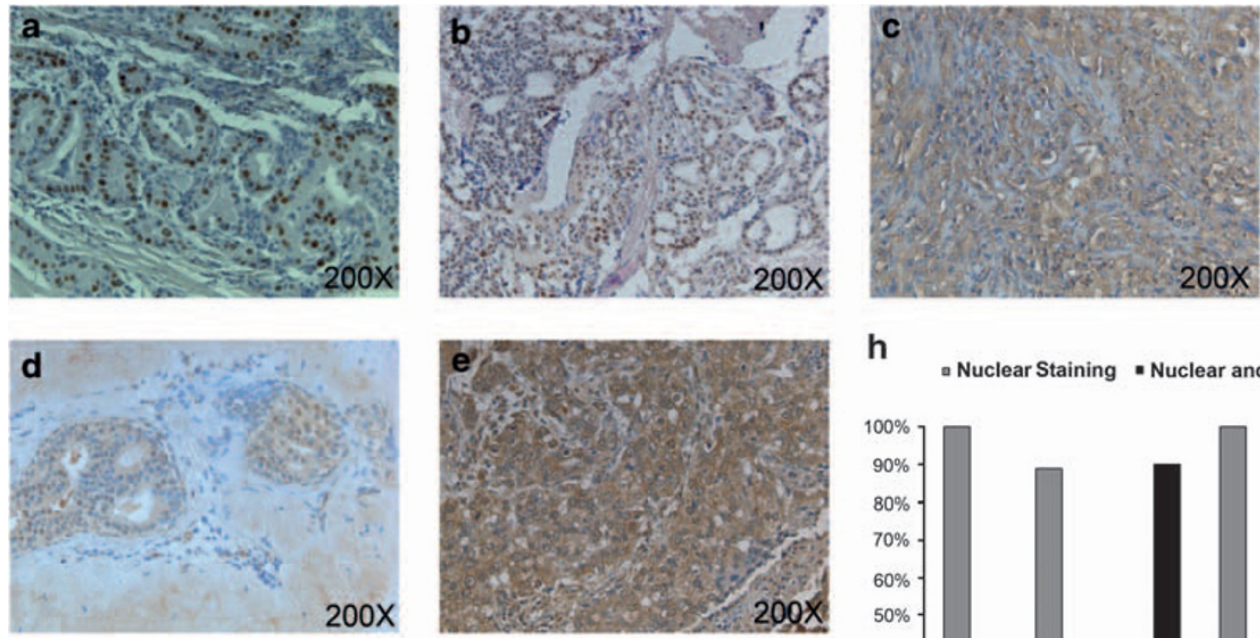

h a Nuclear Staining - Nuclear and Cytoplasmic Staining
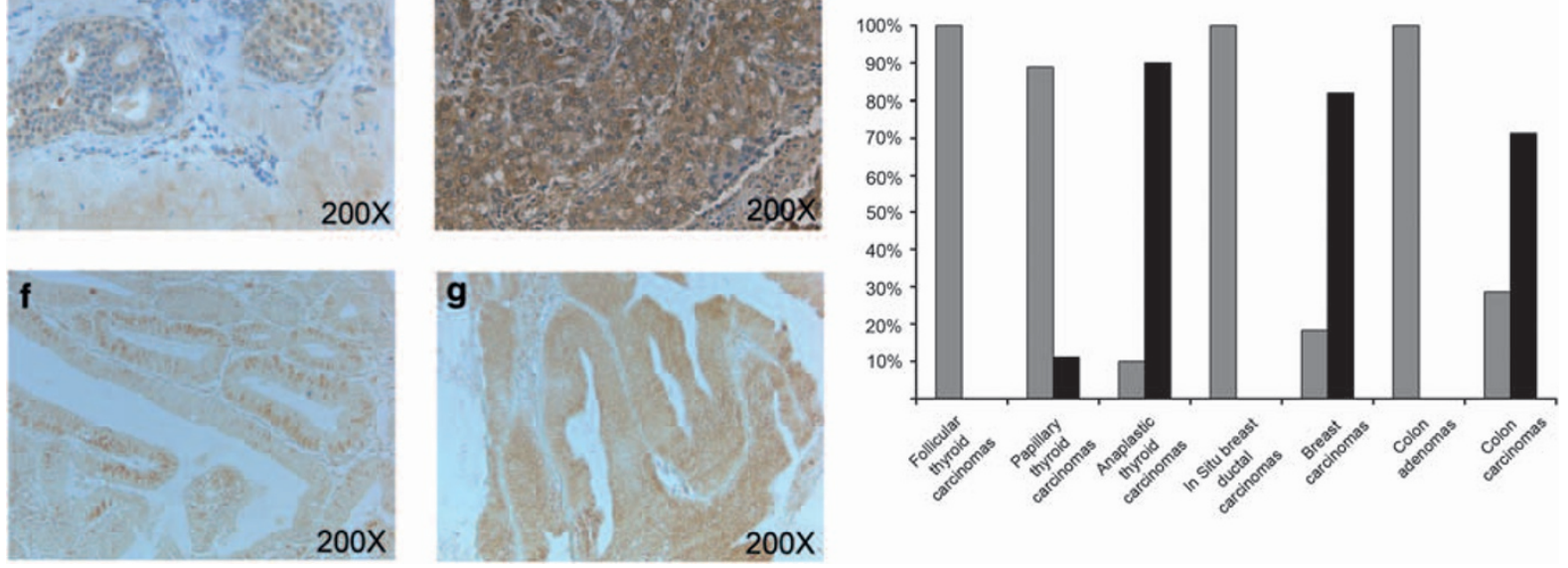

Figure 6 Immunohistochemical analysis of HMGA1 protein expression in human tumors. Paraffin sections were analyzed by immunohistochemistry using home-made rabbit polyclonal anti-HMGA1 antibodies. (a) Immunostaining of a papillary thyroid carcinoma ( $\times 200)$. Specific nuclear immunoreactivity was observed. (b) Immunostaining of a follicular thyroid carcinoma $(\times 200)$. Specific nuclear immunoreactivity was observed in follicular cells. (c) Immunostaining of a anaplastic thyroid carcinoma $(\times 200)$. A strong cytoplasmic staining was observed in undifferentiated cancer cells. (d) Immunostaining of an in situ breast ductal carcinoma showing nuclear immunoreactivity and a very weak cytoplasmic staining $(\times 200)$. (e) Immunostaining of an aggressive ductal breast carcinoma (G3) showing a strong cytoplasmic staining $(\times 200)$. (f) Immunostaining of a colon adenoma with severe dysplasia showing nuclear immunoreactivity. (g) Immunostaining of a colon carcinoma showing a strong cytoplasmic staining in the malignant cells. (h) Chart summarizing immunohistochemical analysis of HMGA1 protein expression in human tumors

Table 1 Correlation between HMGA1 positivity at cytoplasmic level and a higher aggressive tumor histotype

\begin{tabular}{lccc}
\hline & $\begin{array}{c}\text { Nuclear } \\
\text { HMGA1 } \\
\text { staining }\end{array}$ & $\begin{array}{c}\text { Nuclear and } \\
\text { cytoplasmic } \\
\text { HMGA1 } \\
\text { staining }\end{array}$ & $\begin{array}{c}\text { Number } \\
\text { of } \\
\text { samples }\end{array}$ \\
\hline $\begin{array}{l}\text { Follicular thyroid carcinomas } \\
\text { Papillary thyroid carcinomas }\end{array}$ & 10 & 0 & 10 \\
$\begin{array}{l}\text { Anaplastic thyroid } \\
\text { carcinomas }\end{array}$ & 16 & 2 & 18 \\
$\begin{array}{l}\text { In situ breast ductal } \\
\text { carcinomas }\end{array}$ & 8 & 9 & 10 \\
$\begin{array}{l}\text { Breast carcinomas } \\
\text { Colon adenomas }\end{array}$ & 2 & 0 & 8 \\
Colon carcinomas & 12 & 9 & 11 \\
\hline
\end{tabular}

microRNAs ${ }^{33}$ and genes involved in epithelial-mesenchymal transition. $^{34}$

The HMGA proteins induce these effects by directly binding to the DNA, modifying its conformation and, consequently, facilitating the binding of a group of transcriptional factors. They can also influence gene transcription through direct protein-protein interactions with transcription factors leading to the formation of multiprotein complexes at promoters and enhancers of several genes.

Here, we, first, report that HMGA1 is located in the cytoplasm other than in the nucleus of cancer-derived cell lines and in MEFs, which express abundant levels of these proteins. Interestingly, in the same cells, HMGA2 protein was not detected at cytoplasmic level but only in the nucleus, as previously described by others. ${ }^{35}$ Subsequently, we show that HMGA1 has a diffuse mitochondrial localization, in which it is present in the internal compartments as well as on the outer membrane. In these compartments, HMGA1 is able to form complexes with the protein encoded by the $\mathrm{BCl}$-2 oncogene, directly interfering with its binding to $\mathrm{p} 53$, thus counteracting the cytochrome $c$ release. In fact, after a lethal dose of UV light, we found an inverse correlation between cytoplasmic HMGA1 localization and cytochrome $c$ release and apoptosis. Therefore, HMGA1, at the same time, sustains $\mathrm{Bcl}-2$ transcription, as previously demonstrated by our group, ${ }^{19}$ and promotes $\mathrm{Bcl}-2$ activity acting at mitochondria. Finally, by performing experiments using $\alpha$-amanitin, we demonstrate that HMGA1 is able to counteract p53-intrinsic apoptosis independently from its ability to regulate the p53 transcriptional activity.

The interaction of HMGA1 protein with $\mathrm{Bcl}-2$ and the possible impairment of the p53 apoptotic activity would suggest another mechanism by which HMGA1 overexpression can contribute to cancer progression. Therefore, HMGA1 overexpression can impair p53 activity, notwithstanding the absence of $\mathrm{p} 53$ gene mutations and/or deletions, through the already studied transcriptional activity ${ }^{18-20}$ and, in addition, by its ability to displace $\mathrm{Bcl}-2$ from the binding to $\mathrm{p} 53$, and then 
inhibiting p53-mitochondrial apoptosis. Consistently, HMGA1 cytoplasmic localization correlates with a more aggressive histotype of cancer. Indeed, HMGA1 is located in the cytoplasm in anaplastic thyroid carcinomas, colon and breast carcinomas, whereas it is located only at nuclear level in the differentiated thyroid carcinomas, in situ breast carcinomas and in colon adenomas.

Therefore, the data reported here demonstrate the ability of the HMGA1 proteins to localize at mitochondria, where they inhibit apoptosis by displacing p53 from Bcl-2 protein, thus enhancing Bcl-2 oncogenic activity.

\section{Materials and Methods}

Cell culture and transfections. HEK293, GC1, HeLa, HBL100, BT549, MDA-MB-231, MDA-MB-468, MCF7, T47D, ND7 and MEFs cells were maintained in DMEM with $10 \%$ fetal calf serum (Gibco, Carlsbad, CA, USA), glutamine, penicillin and streptomycin. H1299 cells were maintained in RPMl-1640 Medium with $10 \%$ fetal calf serum (Gibco), glutamine, penicillin and streptomycin. Cells were transfected with plasmids by lipofectamine-plus reagent (Invitrogen, Carlsbad, CA, USA) or with WGA (Sigma, St. Louis, MO, USA) by Chariot (Active Motif, Carlsbad, CA, USA) as suggested by the manufacturer.

Expression constructs. The $\mathrm{pCMV} / H$ mga $1 b$ and pHaemagglutinin $(\mathrm{pHA})$ tagged Hmga1 expression plasmids has been previously described. ${ }^{18,36}$ To construct the EGFP-Hmga1b expression vector, the entire Hmga1b coding sequence was amplified by PCR with pairs of primers linked to restriction sites (EcoRl and Kpnl) and cloned in the pEGFP-C2 plasmid (Clontech, Mountain View, CA, USA).

Western blotting and immunoprecipitation assay. Protein extraction, western blotting and co-immunoprecipitation procedures were carried out as reported elsewhere. ${ }^{37-39}$ The antibodies used for immunoprecipitation and western blotting purchased from Santa Cruz Biotechnology (Santa Cruz, CA, USA) were: anti-HA (Y11), anti-Sp1 (H225), anti-p53 (D01), anti-Bcl-2 (100), antiCytochrome $c(7 \mathrm{H} 8)$ and anti- $\gamma$-tubulin (C11); anti-COX IV (3E11), anti-Phospho(ser15) p53 (9284) and anti-Caspase-7 (9492) from Cell Signaling (Danvers, MA, USA); anti-Caspase-9 (MAB8301) purchased from R\&D Systems (Minneapolis, MN, USA); anti-HMGA1 are polyclonal antibodies raised against a synthetic peptide located in the NH2-terminal region and recognize both HMGA1a and HMGA1b isoforms. ${ }^{18}$

In vitro translation and protein-protein binding. The $\mathrm{pET} 2 \mathrm{c}-$ HMGA1b construct was previously described. ${ }^{18}$ His recombinant protein was produced in Escherichia coli BL21 cells. Stationary phase cultures of $E$. coli cells transformed with the plasmid of interest were diluted in LB with ampicillin $(100 \mu \mathrm{g} /$ $\mathrm{ml}$ ), grown at $30^{\circ} \mathrm{C}$ to an $\mathrm{OD}_{600}$ of 0.6 and induced with $0.1 \mathrm{mM}$ IPTG. After an additional $2 \mathrm{~h}$ at $30^{\circ} \mathrm{C}$, the cultures were harvested and resuspended in $10 \mathrm{ml}$ of cold PBS (140 mM NaCl, $20 \mathrm{mM}$ sodium phosphate $\mathrm{pH} 7.4), 1 \mathrm{mM}$ phenylmethylsulfonyl fluoride and protease inhibitors (Boehringer, Manheim, Germany). The cells were broken by French Press. The supernatant was purified by using nickelagarose beads supplied with the His-Trap purification kit (Amersham Pharmacia, Buckinghamshire, England, UK) following the manufacturer's instructions, eluted with $500 \mathrm{mM}$ imidazol and dialysed in PBS. The purified Bcl-2 and p53 proteins were, respectively, purchased from GenWay (San Diego, CA, USA) and BD Pharmingen (Franklin Lakes, NJ, USA). The recombinant proteins were subjected to in vitro protein-protein binding in NETN buffer $(20 \mathrm{mM}$ Tris- $\mathrm{HCl} \mathrm{pH} \mathrm{8.0,100} \mathrm{mM}$ $\mathrm{NaCl}, 1 \mathrm{mM}$ EDTA and $0.5 \%$ Nonidet P-40) for $1 \mathrm{~h}$ at $4{ }^{\circ} \mathrm{C}$. Recombinant proteins and Abs were incubated for $3 \mathrm{~h}$ and then supplemented with protein A-sepharose or G-sepharose beads (Millipore, Billerica, MA, USA). The resins were then extensively washed in the same buffer. The bound proteins were separated by SDS-PAGE, and analyzed by western blotting.

Immunofluorescence. Cells plated in $35-\mathrm{mm}$ dishes were fixed in $2 \%$ formaldehyde in PBS and permeabilized in a solution of $0.25 \%$ Triton X-100 in PBS. Immunofluorescence was obtained with the anti-HA 12CA5 moAb (Roche, Indianapolis, IN, USA) and the FITC-conjugated goat anti mouse IgG (Jackson, West Grove, PA, USA). Cells were stained simultaneously for DNA with Hoechst
33342 before observation with a fluorescent microscope (Zeiss, Oberkochen, Germany). For mitochondrial staining, cells transfected with EGFP-HMGA1b were stained with Mito-ID Red Detection Kit as suggested by the manufacturer.

Viability, apoptosis and caspase detection. Apoptosis was monitored by FACS, measuring the mitochondrial membrane potential (DF), determining the activation of Caspase-9 and TUNEL assay. Cells were harvested, pooled with the supernatant, washed once in PBS with $\mathrm{Ca}^{2+} / \mathrm{Mg}^{2+}$ and processed for the different assays. For FACS analysis, cells were trypsinized, fixed in $70 \%$ ethanol and stored at $4{ }^{\circ} \mathrm{C}$ for a few days. Then, cells were washed with PBS without $\mathrm{Ca}^{2+}$ and $\mathrm{Mg}^{2+}$, stained with $50 \mu \mathrm{g} / \mathrm{ml}$ propidium iodide containing RNase $(20 \mu \mathrm{g} / \mathrm{ml})$ and analyzed with a FACS Calibur cytofluorimeter. For the measurement of the DF, the JC-1 staining was used. After washing in PBS with $\mathrm{Ca}^{2+} / \mathrm{Mg}^{2+}$, cells were resuspended in complete medium and incubated with $2.5 \mathrm{mg} / \mathrm{ml} \mathrm{JC}-1$ (Molecular Probes) for $20 \mathrm{~min}$ at room temperature in the dark. After two washes in PBS with $\mathrm{Ca}^{2+} / \mathrm{Mg}^{2+}$, samples were placed on ice and immediately analyzed by a BD FACScan cytofluorimeter by using the BD CellQuest software package (BD, Franklin Lakes, NJ, USA). TUNEL assay were performed according to the manufacturer's instructions (Roche Biochemicals, Indianapolis, IN, USA). Caspase-9 colorimetric assay (PromoKine, Heidelberg, Germany) was analyzed according to the manufacturer's instructions.

Isolation of nuclear/cytoplasmic fractions. Nuclear and cytoplasmic fractions were prepared as follows: $1-2 \times 10^{6}$ cells, scraped off the plate with PBS, were resuspended in hypotonic lysis buffer (10 mM HEPES pH 7.9, $10 \mathrm{mM}$ $\mathrm{KCl}, 0.1 \mathrm{mM}$ EDTA, $0.1 \mathrm{mM}$ EGTA) added with protease inhibitors (Roche). After resuspension, NP-40 was added to a final concentration of $0.6 \%$ and the nuclei were isolated by centrifugation at 10000 r.p.m. for $30 \mathrm{~s}$ at $4{ }^{\circ} \mathrm{C}$. After removal of the supernatant (i.e. the cytoplasmic extract), nuclei were resuspended in nuclear extract buffer (20 mM HEPES pH 7.9, 25\% glycerol, $0.4 \mathrm{M} \mathrm{NaCl}, 0.1 \mathrm{mM}$ EDTA, $0.1 \mathrm{mM}$ EGTA), rocked for $15 \mathrm{~min}$ at $4^{\circ} \mathrm{C}$ and then recovered by centrifugation at 14000 r.p.m. for $5 \mathrm{~min}$ at $4^{\circ} \mathrm{C}$.

Isolation of mitochondria and treatment with proteinase $K$ in vitro. Mitochondria were isolated by differential centrifugation, using Mitochondria Fractionation Kit (BioVision, San Francisco, CA, USA). For enzymatic digestion, isolated mitochondria were resuspended in suspension buffer and treated with proteinase $\mathrm{K} 0.2 \mathrm{mg} / \mathrm{ml}$ for $20 \mathrm{~min}$ at $30^{\circ} \mathrm{C}$ in the presence or absence of Triton X-100 ( $1 \%$ final concentration). Phenylmethylsulfonyl fluoride was then added to a final concentration of $2 \mathrm{mM}$ to stop the reaction.

Cytochrome $c$ release from isolated, purified mitochondria. Intact mitochondria were isolated as above described and incubated at $37^{\circ} \mathrm{C}$ for $1 \mathrm{~h}$ with His-HMGA1b and recombinant p53 in MSB buffer ( $400 \mathrm{mM}$ mannitol,

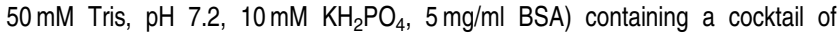
protease inhibitors. Samples were centrifuged at 5500 r.p.m. for $15 \mathrm{~min}$ at $4{ }^{\circ} \mathrm{C}$. The resulting supernatant and pelleted mitochondrial fractions were analyzed by western blot. Pelleted mitochondria were washed two times with MSB buffer before analysis.

RNA extraction and quantitative reverse transcription PCR (qRT-PCR). Total RNA was extracted from tissues and cell cultures with Trizol (Gibco) according to the manufacturer's instructions. For PUMA and NOXA mRNA detection, we reverse transcribed total RNA from cell lines by using the QuantiTect Reverse Transcription Kit (Qiagen, Hilden, Germany), and then qRTPCR for PUMA and NOXA was performed by using Power SYBR Green PCR Master Mix (Applied Biosystems, Foster City, CA, USA) and the following primers: PUMA for: $5^{\prime}$-GACCTCAACGCACAGTACGA-3' and PUMA rev: $5^{\prime}$-GAGATTGTA CAGGACCCTCCA-3'; NOXA for: $5^{\prime}$-GGAGTGGCCAACTTCCAG-3' and NOXA rev: 5'-AGCTGCGTGTAGTCGATGG-3'; G6PD for: 5'-ACAGAGTGAGCCCTTCT TCAA-3' and G6PD rev: $5^{\prime}$-ATAGGAGTTGCGGGCAAAG-3'. The $2^{-\Delta \Delta C t}$ formula was used to calculate the differential gene expression.

Immunohistochemistry. For immunohistochemistry, $6 \mu \mathrm{m}$ paraffin sections were deparaffinised and then placed in a solution of absolute methanol and $0.3 \%$ hydrogen peroxide for $30 \mathrm{~min}$ and then washed in PBS before immunoperoxidase staining. The slides were then incubated overnight at $4{ }^{\circ} \mathrm{C}$ in a humidified chamber with the antibodies diluted 1:100 in PBS. The slides were subsequently incubated with biotinylated goat anti-rabbit IgG for 20 min (Vectostain ABC kits, Vector 
Laboratories, Burlingame, CA, USA) and then with premixed reagent $\mathrm{ABC}$ (Vector) for $20 \mathrm{~min}$. The immunostaining was performed by incubating the slides in diaminobenzidine (DAB-DAKO) solution containing $0.06 \mathrm{mM}$ DAB and $2 \mathrm{mM}$ hydrogen peroxide in $0.05 \%$ PBS, $\mathrm{pH} 7.6$, for $5 \mathrm{~min}$, and, after chromogen development, the slides were washed, dehydrated with alcohol and xylene and mounted with cover slips using a permanent mounting medium (Permount). The antibodies used in this study were raised against the synthetic peptide SSSKQQPLASKQ specific for the HMGA protein. They were affinity purified against the synthetic peptide. ${ }^{18}$ Tissue samples were scored as positive for immunohistochemistry when tissue immunoreactivity was detected in at least $10 \%$ of the cells. Negative controls were performed by omitting the first antibody. The specificity of the reaction was confirmed by the lack of tissue immunoreactivity after preincubation of the antibody with molar excess of the HMGA1 synthetic peptide.

\section{Conflict of Interest}

The authors declare no conflict of interest.

Acknowledgements. This work was supported by grants (IG11477 and MFAG11702) from the Associazione Italiana Ricerca sul Cancro (AIRC), and the Ministero dell'Università e della Ricerca Scientifica e Tecnologica (MIUR). This work was supported from NOGEC-Naples Oncogenomic Center. We thank the Associazione Partenopea per le Ricerche Oncologiche (APRO) for its support. Francesco Esposito is recipient of a FIRC fellowship.

1. Johnson KR, Lehn DA, Reeves R. Alternative processing of mRNAs encoding mammalian chromosomal high-mobility-group proteins HMG-I and HMG-Y. Mol Cell Biol 1989; 9: 2114-2123.

2. Nagpal S, Ghosn C, DiSepio D, Molina Y, Sutter M, Klein ES et al. Retinoid-dependent recruitment of a histone $\mathrm{H} 1$ displacement activity by retinoic acid receptor. J Biol Chem 1999; 274: 22563-22568.

3. Manfioletti G, Giancotti V, Bandiera A, Buratti E, Sautière P, Cary P et al. cDNA cloning of the HMGI-C phosphoprotein, a nuclear protein associated with neoplastic and undifferentiated phenotypes. Nucleic Acids Res 1991; 19: 6793-6797.

4. Thanos D, Maniatis T. The high mobility group protein HMG I(Y) is required for NF-kappa B-dependent virus induction of the human IFN-beta gene. Cell 1992; 71: 777-789.

5. Grosschedl R, Giese K, Pagel J. HMG domain proteins: architectural elements in the assembly of nucleoprotein structures. Trends Genet 1994; 10: 94-100.

6. Zhou X, Benson KF, Ashar HR, Chada K. Mutation responsible for the mouse pygmy phenotype in the developmentally regulated factor HMGI-C. Nature 1995; 376: 771-774.

7. Chiappetta G, Avantaggiato V, Visconti R, Fedele M, Battista S, Trapasso F et al. High level expression of the HMGI (Y) gene during embryonic development. Oncogene 1996; 13: $2439-2446$.

8. Chiappetta G, Tallini G, De Biasio MC, Manfioletti G, Martinez-Tello FJ, Pentimalli F et al. Detection of high mobility group I HMGI(Y) protein in the diagnosis of thyroid tumors: $\mathrm{HMGI}(\mathrm{Y})$ expression represents a potential diagnostic indicator of carcinoma. Cancer Res 1998; 58: 4193-4198.

9. Fedele M, Bandiera A, Chiappetta G, Battista S, Viglietto G, Manfioletti G et al. Human colorectal carcinomas express high levels of high mobility group $\mathrm{HMGI}(\mathrm{Y})$ proteins. Cancer Res 1996; 56: 1896-1901.

10. Tamimi Y, van der Poel HG, Denyn MM, Umbas R, Karthaus HF, Debruyne FM et al. Increased expression of high mobility group protein $\mathrm{I}(\mathrm{Y})$ in high grade prostatic cancer determined by in situ hybridization. Cancer Res 1993; 53: 5512-5516.

11. Abe N, Watanabe T, Izumisato $Y$, Masaki T, Mori T, Sugiyama M et al. Diagnostic significance of high mobility group $\mathrm{I}(\mathrm{Y})$ protein expression in intraductal papillary mucinous tumors of the pancreas. Pancreas 2002; 25: 198-204.

12. Bandiera A, Bonifacio D, Manfioletti G, Mantovani F, Rustighi A, Zanconati $F$ et al. Expression of $\mathrm{HMGI}(\mathrm{Y})$ proteins in squamous intraepithelial and invasive lesions of the uterine cervix. Cancer Res 1998; 58: 426-431.

13. Masciullo V, Baldassarre G, Pentimalli F, Berlingieri MT, Boccia A, Chiappetta G et al. HMGA1 protein over-expression is a frequent feature of epithelial ovarian carcinomas. Carcinogenesis 2003; 24: 1191-1198.

14. Chiappetta G, Botti G, Monaco M, Pasquinelli R, Pentimalli F, Di Bonito M et al. HMGA1 protein overexpression in human breast carcinomas: correlation with ErbB2 expression. Clin Cancer Res 2004; 10: 7637-7644.

15. Fusco A, Fedele M. Roles of the HMGA proteins in cancer. Nat Rev Cancer 2007; 7: 899-910.

16. Berlingieri MT, Manfioletti G, Santoro M, Bandiera A, Visconti R, Giancotti V et al. Inhibition of HMGI-C protein synthesis suppresses retrovirally induced neoplastic transformation of rat thyroid cells. Mol Cell Biol 1995; 15: 1545-1553.

17. Scala S, Portella G, Fedele M, Chiappetta G, Fusco A. Adenovirus-mediated suppression of $\mathrm{HMGI}(\mathrm{Y})$ protein synthesis as potential therapy of human malignant neoplasias. Proc Natl Acad Sci USA 2000; 11: 4256-4261.

18. Pierantoni GM, Rinaldo C, Esposito F, Mottolese M, Soddu S, Fusco A. High Mobility Group A1 (HMGA1) proteins interact with p53 and inhibit its apoptotic activity. Cell Death Differ 2006; 13: 1554-1563.

19. Esposito F, Tornincasa M, Chieffi P, De Martino I, Pierantoni GM, Fusco A. High-mobility group A1 proteins regulate p53-mediated transcription of Bcl-2 gene. Cancer Res 2010; 70: 5379-5388.

20. Pierantoni GM, Rinaldo C, Mottolese M, Di Benedetto A, Esposito F, Soddu S et al. Highmobility group $A 1$ inhibits $p 53$ by cytoplasmic relocalization of its proapoptotic activator HIPK2. J Clin Invest 2007; 117: 693-702.

21. Reef S, Zalckvar E, Shifman O, Bialik S, Sabanay H, Oren M et al. A short mitochondria form of p19ARF induces autophagy and caspase-independent cell death. Mol Cell 2006; 22: $463-475$.

22. Akao Y, Otsuki Y, Kataoka S, Ito Y, Tsujimoto Y. Multiple subcellular localization of bcl-2: detection in nuclear outer membrane, endoplasmic reticulum membrane, and mitochondrial membranes. Cancer Res 1994; 54: 2468-2471.

23. Mihara M, Erster S, Zaika A, Petrenko O, Chittenden T, Pancoska P et al. p53 has a direct apoptogenic role at the mitochondria. Mol Cell 2003; 11: 577-590.

24. Deng X, Gao F, Flagg T, Anderson J, May S. BCL2's flexible loop domain regulates p53 binding and survival. Mol Cell Biol 2006; 26: 4421-4434.

25. Chipuk JE, Green DR. Dissecting p53-dependent apoptosis. Cell Death Differ 2006; 13: 994-1002.

26. Chipuk JE, Kuwana T, Bouchier-Hayes L, Droin NM, Newmeyer DD, Schuler M et al. Direct activation of Bax by p53 mediates mitochondria membrane permeabilization and apoptosis. Science 2004; 303: 1010-1014.

27. Arima Y, Nitta M, Kuninaka S, Zhang D, Fujiwara T, Taya Y et al. Transcriptional blockade induces p53-dependent apoptosis associated with translocation of p53 to mitochondria. J Biol Chem 2005; 280: 19166-19176.

28. Fedele M, Visone R, De Martino I, Troncone G, Palmieri D, Battista S et al. HMGA2 induces pituitary tumorigenesis by enhancing E2F1 activity. Cancer Cell 2006; 9: 459-471.

29. Vallone D, Battista S, Pierantoni GM, Fedele M, Casalino L, Santoro M et al. Neoplastic transformation of rat thyroid cells requires the junB and fra- 1 gene induction which is dependent on the HMGI-C gene product. EMBO J 1997; 16: 5310-5321.

30. Tessari MA, Gostissa M, Altamura S, Sgarra R, Rustighi A, Salvagno C et al. Transcriptional activation of the cyclin A gene by the architectural transcription factor HMGA2. Mol Cell Biol 2003; 23: 9104-9116.

31. Reeves $\mathrm{R}$, Adair JE. Role of high mobility group (HMG) chromatin proteins in DNA repair. DNA Repair 2005; 4: 926-938.

32. Kim HP, Kelly J, Leonard WJ. The basis for IL-2-induced IL-2 receptor alpha chain gene regulation: importance of two widely separated IL-2 response elements. Immunity 2001; 15: 159-172.

33. De Martino I, Visone R, Fedele M, Petrocca F, Palmieri D, Martinez Hoyos J et al. Regulation of microRNA expression by HMGA1 proteins. Oncogene 2009; 28: 1432-1442.

34. Thuault S, Valcourt U, Petersen M, Manfioletti G, Heldin CH, Moustakas A. Transforming growth factor-beta employs HMGA2 to elicit epithelial-mesenchymal transition. J Cell Biol 2006; 174: 175-183.

35. Cattaruzzi G, Altamura S, Tessari MA, Rustighi A, Giancotti V, Pucillo C et al. The second AT-hook of the architectural transcription factor HMGA2 is determinant for nuclear localization and function. Nucleic Acids Res 2007; 35: 1751-1760.

36. Pierantoni GM, Fedele M, Pentimalli F, Benvenuto G, Pero R, Viglietto G et al. High mobility group $I(Y)$ proteins bind HIPK2, a serine-threonine kinase protein which inhibits cell growth. Oncogene 2001; 20: 6132-6141.

37. Pallante P, Federico A, Berlingieri MT, Bianco M, Ferraro A, Forzati $F$ et al. Loss of the CBX7 gene expression correlates with a highly malignant phenotype in thyroid cancer. Cancer Res 2008; 68: 6770-6778.

38. Federico A, Pallante P, Bianco M, Ferraro A, Esposito F, Monti M et al. Chromobox protein homologue 7 protein, with decreased expression in human carcinomas, positively regulates E-cadherin expression by interacting with the histone deacetylase 2 protein. Cancer Res 2009; 69: 7079-7087.

39. Pentimalli F, Dentice M, Fedele M, Pierantoni GM, Cito L, Pallante P et al. Suppression of HMGA2 protein synthesis could be a tool for the therapy of well differentiated liposarcomas overexpressing HMGA2. Cancer Res 2003; 63: 7423-7427.

(c)

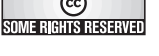
published by Nature Publishing Group. This work is Derivative Works 30 Unported visit http://creativecommons.org/licenses/by-nc-nd/3.0/ 


\title{
Retraction
}

\section{Retraction to: High-mobility group A1 protein inhibits p53-mediated intrinsic apoptosis by interacting with Bcl-2 at mitochondria}

\author{
F Esposito, M Tornincasa, A Federico, G Chiappetta, GM Pierantoni and A Fusco
}

Cell Death and Disease (2014) 5, e1206; doi:10.1038/cddis.2014.163; published online 1 May 2014

Retraction to: Cell Death and Disease (2012) 3, e383; doi:10.1038/cddis.2012.126; published online 30 August 2012

The Editorial Board of Cell Death and Disease is retracting the above article (PMID 22932725).

A reader contacted the Editors about apparent duplications in Figures $1 \mathrm{~b}$ and 2c, and possible splicing of an image in Figure 3c. Concerns were subsequently raised about the similarity of the tubulin loading controls in Figure $1 \mathrm{~b}$ to those that appeared in Figure 1c of Cell Death and Differentiation 2006; 13: 1554-63 (PMID 16341121), a paper that was retracted by the authors on 6 December 2013.

Because the Authors were unable to provide the original source files that were used to generate the figures in question, the Editorial Board is retracting this publication. 